\title{
ALGINATO BACTERIANO: ASPECTOS TECNOLÓGICOS, CARACTERÍSTICAS E PRODUÇÃO
}

\author{
Crispin Humberto Garcia-Cruz*, Ulisses Foggetti e Adriana Navarro da Silva
}

Instituto de Biociências, Letras e Ciências Exatas, Universidade Estadual Paulista, R. Cristóvão Colombo, 2265, 15054-000 São

José do Rio Preto - SP, Brasil

Recebido em 14/5/07; aceito em 30/11/07; publicado na web em 4/9/08

\begin{abstract}
BACTERIAL ALGINATE: TECHNOLOGICAL ASPECTS, CHARACTERISTICS AND PRODUCTION. Alginate is a biopolymer used for a variety of industrial applications, for example, in the textiles, cosmetics, foods, agricultural and biotechnological industries. This biopolymer is traditionally extracted from some brown seaweeds (Phaeophyceae) and can be produced by bacteria isolated from soil, as Azotobacter vinelandii, like capsular polysaccharide using glucose, sucrose, among others as carbon sources. The main difference between the alginate of seaweed and the bacterial ones, is the biggest degree of acetylation of this last one, with great influence in the gel force. These chemical characteristics and production of bacterial alginate are presented in this work.
\end{abstract}

Keywords: bacterial alginate; biopolymer; Azotobacter vinelandii.

\section{INTRODUÇÃO}

Os alginatos são extraídos de várias espécies de algas marinhas marrons (Phaeophyta), onde agem como componente estrutural na parede celular e nos espaços intracelulares, promovendo rigidez e ao mesmo tempo flexibilidade à parede celular, compreendendo cerca de $40 \%$ da matéria seca destes organismos. Anualmente, a indústria produz cerca de 30 mil t de alginatos, o que não chega a $10 \%$ do material biossintetizado anualmente pelas algas marinhas naturais. Estas macroalgas podem também ser cultivadas em verdadeiras fazendas marinhas, como é feito em grande parte da China.

Embora as paredes celulares das algas marinhas marrons possuam muito em comum com as paredes celulares de plantas superiores, o ácido algínico encontrado em todas as espécies conhecidas de Phaeophyceae não está presente em outros tecidos vegetais. Entretanto é sintetizado por bactérias, como Pseudomonas spp. e Azotobacter vinelandii, como uma mucilagem extracelular (polissacarídeo capsular) e difere do ácido algínico presente nas algas apenas por ser mais acetilado.

O ácido algínico é insolúvel em água à temperatura ambiente, tornando-se solúvel em temperaturas elevadas. Portanto, os sais de sódio, cálcio e potássio do ácido algínico, solúveis em água, são preferidos para o emprego na indústria de alimentos. O composto mais amplamente usado é o alginato de sódio. Em muitas aplicações, o alginato de sódio solúvel torna-se insolúvel por meio da adição de cátions divalentes, geralmente cálcio, resultando em géis ou filmes. Tais géis não são termo-reversíveis quando altas concentrações de cálcio são utilizadas, podendo ser termo-reversíveis em baixas concentrações. A força do gel depende da natureza do cátion divalente.

O constante incremento nas aplicações deste polímero nos setores alimentício e farmacêutico e a constante poluição dos mares, uma vez que, as algas necessitam de água límpida para seu crescimento, levou a uma pesquisa continuada visando entender melhor as vias bioquímicas, a função fisiológica e a biologia das bactérias produtoras deste polímero, visando a regulação da sua formação e composição, e ainda a otimização do processo de produção.

\footnotetext{
*e-mail: crispin@ibilce.unesp.br
}

\section{ALGINATO DE ALGAS VERSUS ALGINATO BACTERIANO}

O termo "alginato" refere-se a um grupo de polissacarídeos que ocorrem naturalmente na parede celular de algas marinhas marrons (Phaeophyceae) onde eles existem como o sal misto de cálcio-sódiopotássio do ácido algínico. ${ }^{1,2}$

As algas marrons (Phaeophyceae) que contêm alginato constituem-se em uma família diversificada de plantas. Crescem em praias rochosas ou nas áreas do oceano com fundo límpido e rochoso. Algumas espécies são encontradas ao nível da maré alta; outras ocorrem em um cinturão ao longo da praia, a profundidade menor que $38 \mathrm{~m}$ (o limite para a penetração da luz solar). Somente algumas espécies de algas marrons são utilizadas como fonte comercial de alginatos. A alga gigante Macrocystis pyrifera, que cresce abundantemente nas costas da América do Norte e do Sul, Nova Zelândia, Austrália e África, é a principal fonte de suprimento mundial de alginato. Também são utilizadas variedades de Laminaria, Ecklonia e Aschophyllum nodosum, as quais são colhidas por alguns produtores. Essas diferentes espécies de algas marrons produzem alginatos com diferentes proporções de ácido poligulurônico na estrutura, resultando assim em diferentes propriedades e funcionalidades destes compostos. ${ }^{3}$

O formaldeído é usualmente adicionado à alga marrom, póscolheita, para evitar o crescimento microbiano durante sua estocagem e fixar os polifenóis nas algas antes da extração do alginato. Sabendo que o formaldeído é tóxico, alergênico e possivelmente carcinogênico, a adição de sal na Ascophyllum nodosum (Phaeophyceae) foi testada como alternativa por Moen e colaboradores. ${ }^{4}$ As algas foram colhidas na costa da Noruega, onde a salinidade é de aproximadamente $30 \%$ do final do outono até o começo da primavera e depois de colhidas foram estocadas a $22 \pm 2{ }^{\circ} \mathrm{C}$ sob determinadas condições. Caso as amostras de algas sejam estocadas sem tratamentos ocorre a perda de suas qualidades, assim como do material para produção do alginato em até 14 dias. Os tratamentos com formaldeído ( $2 \%$ peso/peso) ou com $20 \% \mathrm{NaCl}$ preservam as algas por até 46 dias; embora a técnica com $\mathrm{NaCl}$ seja menos agressiva, ainda é inconveniente e onerosa para a indústria do alginato, pois é necessário o controle de temperatura, $\mathrm{pH}$, oxigênio, assim como do sal, fazendo com que o método mais utilizado comercialmente seja o de adição de formaldeído. ${ }^{4}$

A estrutura do ácido algínico consiste de cadeias lineares de resí- 
duos de ácido $\beta$-D-manurônico $(\mathrm{M})$ unidos por ligações tipo $(1 \rightarrow 4)$ e resíduos de seu epímero, o ácido $\alpha$-L-gulurônico $(\mathrm{G})$, em várias proporções. Estes resíduos estão arranjados na forma de blocos de ácidos manurônico $(\mathrm{M})$ ou gulurônico $(\mathrm{G})$, ligados de forma que a seqüência destes resíduos na molécula seja alternada. ${ }^{1,5-9}$ Segundo Clementi e colaboradores,${ }^{10}$ a molécula deste polímero é constituída por blocos homopoliméricos, M- e G-, e por blocos heteropoliméricos MG- (Figura 1). Na molécula, a disposição espacial dos monômeros se dá segundo a posição energética mais favorável. Para blocos $\mathrm{G}-\mathrm{G}$ esta é uma posição em forma de cadeira, ${ }^{1} \mathrm{C}_{4}$, sendo os monômeros unidos por ligação glicosídica $\alpha(1 \rightarrow 4)$. Para $\mathrm{M}-\mathrm{M}$ trata-se da posição ${ }^{4} \mathrm{C}_{1}$, sendo a ligação glicosídica do tipo $\beta(1 \rightarrow 4)$. $\mathrm{O}$ grupo carboxílico é responsável por uma ligação glicosídica equatorial/ equatorial em $\mathrm{M}-\mathrm{M}$, uma ligação glicosídica axial/axial em $\mathrm{G}-\mathrm{G}$ e uma ligação glicosídica equatorial/axial para $\mathrm{M}-\mathrm{G} .{ }^{11}$

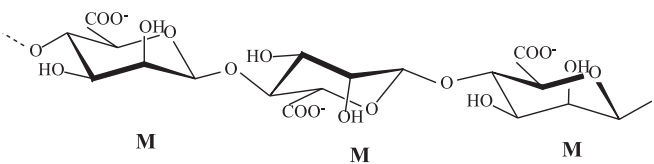

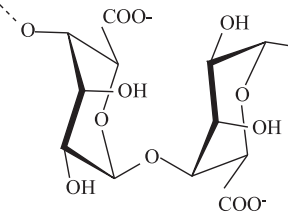

G

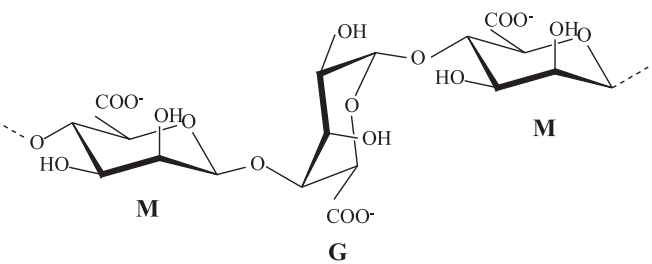

Figura 1. Estrutura dos blocos homopoliméricos $M-e$ - $e$ dos blocos heteropoliméricos $M G$-, que constituem a molécula de alginato. Em (A) tem-se uma seqüência $M-M$; em (B) uma seqüência $G-G$ e em $(C)$ uma seqüência $M-G-M$. Adaptada da ref. 9

Alginatos isolados de diferentes fontes naturais variam no comprimento e distribuição dos diferentes tipos de blocos. ${ }^{1}$ Os alginatos são produzidos por bactérias e por algas marinhas marrons, e os resíduos de manuronato dos alginatos bacterianos, mas não os de algas, são acetilados nas posições O-2 e/ou O-3. ${ }^{12,13}$ A variabilidade nas estruturas dos blocos de monômeros (peso molecular, proporção e distribuição relativa dos dois monômeros, $\mathrm{M} \mathrm{e} \mathrm{G}$, ao longo da molécula) e a acetilação influem grandemente nas propriedades físico-químicas e reológicas do polímero, e a base biológica para esta variabilidade é, portanto, de grande importância científica e prática. ${ }^{11,14,15}$

No momento atual a produção é concentrada principalmente no cultivo de algas marinhas marrons, mas várias bactérias pertencentes ao gênero Pseudomonas e Azotobacter também produzem alginato ${ }^{16-20}$ e a estrutura dos blocos de resíduos dos monômeros é similar nos alginatos produzidos por algas marinhas e sintetizados por $A$. vinelandii. ${ }^{21}$ De fato, segundo Gorin e Spencer,${ }^{17}$ a rotação específica de alginato de sódio bacteriano é muito próxima da rotação do alginato de sódio derivado de algas, sugerindo, assim, que as configurações glicosídicas sejam similares. Em contraste, todos os alginatos de Pseudomonas embora possuam monômeros $\mathrm{G}$, não possuem seqüências destes monômeros, ou seja, não possuem blocos G. ${ }^{12,22}$

Embora as algas marinhas sejam, normalmente, a fonte comercial de alginatos, os de origem bacteriana vêm sendo sugeridos como possíveis substitutos para os alginatos de algas. Para este fim, estudos focaram primeiro a bactéria patogênica oportunista Pseudomonas aeruginosa, e depois, três espécies não-patogênicas de Pseudomonas, incluindo P. mendocina, P. putida, e P. fluorescens, e ainda, a bactéria do solo Azotobacter vinelandii. ${ }^{23}$

A maior parte do nosso conhecimento sobre a genética da biossíntese de alginato se origina de estudos de Pseudomonas aeruginosa, principalmente por causa da relevância médica desta bactéria, como um importante microrganismo patogênico oportunista, para humanos, em pacientes sofrendo de fibrose cística. ${ }^{24-26}$ Nesta, os alginatos têm papel importante como um fator de virulência. A razão para isto parece ser a formação de um biofilme de alginato, o qual facilita a colonização do pulmão. ${ }^{27} A$. vinelandii e $P$. aeruginosa produzem alginato como um polissacarídeo extracelular nas células vegetativas, enquanto que na produção de alginato por $A$. vinelandii está envolvido um processo de diferenciação levando ao assim chamado "cisto". ${ }^{28}$ Este cisto é formado pelo acúmulo intracelular de poliidroxibutirato delimitado dentro do citoplasma por uma membrana lipoprotéica de parede dupla, que ocorre quando a célula bacteriana se encontra num meio onde, em geral, há excesso de uma fonte de carbono e limitação de nitrogênio, fósforo ou oxigênio. Quando ocorre a exaustão da fonte de carbono, estes cistos oxidam de maneira rápida (por meio da ativação da enzima PHB depolimerase) e são utilizados como fontes de energia.

O potencial dos alginatos produzidos por bactérias, como polímeros industriais, é ainda um assunto controverso. Entretanto, a possibilidade de usar matérias-primas livres de variações sazonais e geográficas, e também cepas selecionadas, sob condições operacionais cuidadosamente controladas, de maneira a atender aplicações específicas em biotecnologia e biomedicina, pode ser suficiente para compensar a produção relativamente baixa, e grau de acetilação relativamente alto, dos polímeros bacterianos. ${ }^{29}$

\section{APLICAÇÕES E CARACTERÍSTICAS QUÍMICAS DO ALGINATO BACTERIANO}

O alginato é um grupo de polissacarídeos normalmente extraído de paredes celulares de algas marrons, sendo utilizado numa ampla variedade de fins industriais, como agente estabilizante, espessante e gelificante, na indústria de alimentos e também para imobilizar células nas indústrias farmacêuticas e biotecnológicas. ${ }^{30,31}$ Os géis de alginato são capazes de formar micro-leitos e incorporar enzimas ou células vivas inteiras, e esta aplicação tem despertado interesse na indústria de alimentos, na biotecnologia, e no setor biomédico. ${ }^{32}$

Na indústria de alimentos, os alginatos são largamente utilizados como aditivos com a capacidade de aumentar a viscosidade, estabilizar, emulsificar e gelificar soluções aquosas. A principal aplicação provavelmente é na produção de sorvete, na qual é utilizado para prevenir a cristalização e o encolhimento, originando um produto homogêneo. Outra aplicação é em molhos para saladas, onde o alginato de sódio ou o éster de alginato de propileno glicol (PGA) são usados como estabilizantes para evitar a separação de fases; com a mesma finalidade é aplicado em maioneses para estabilizar as emulsões fase água/óleo. Devido ao seu conteúdo calórico baixo (1,4 Kcal/g) estes polímeros podem ser usados como "agente de corpo" na formulação de produtos de baixa caloria, como maioneses e massas. ${ }^{10}$

Os alginatos são muito empregados na área de análogos de frutas ou produtos tipo imitação. Em 1946, Peschardt patenteou um processo para fazer cerejas artificiais utilizando uma solução colorida e aromatizada de alginato em açúcar, que era adicionada em forma 
de gotas a uma solução coagulante de sais solúveis de cálcio. Uma película de alginato de cálcio insolúvel formava-se imediatamente em volta da superfície das gotas. Após mergulhá-las em uma solução de sais de cálcio, os íons penetravam por difusão em seu interior para fazer a gelificação. Vários tipos de texturas podiam ser obtidas através do controle adequado do tipo de sal de cálcio, concentração, tempo e temperatura, etc. Estas cerejas fabricadas não eram afetadas pelo calor e podiam ser perfeitamente usadas em produtos de panificação. Além disso, tinham a vantagem de apresentar uniformidade no tamanho, peso e qualidade. Foram desenvolvidos produtos similares utilizando purês de cereja em um sistema de gelificação de alginato, comercializados com o nome de "bolas moldadas de cereja". ${ }^{33}$ Outros produtos tipo imitação encontrados comercialmente são: imitação de fatias de pimentão para recheios de azeitonas, de anéis de cebola, caviar, carne, pescados, produtos marinhos, etc. ${ }^{33}$

\section{PRODUÇÃO DE ALGINATO BACTERIANO}

A produção de alginato não é uma característica exclusiva de algas marinhas marrons, pois foi descoberto que algumas bactérias sintetizam polímeros semelhantes a alginatos. ${ }^{34-37}$

Inicialmente, Linker e Jones,${ }^{20}$ fizeram esta descoberta na bactéria patogênica Pseudomonas aeruginosa e, posteriormente, Gorin e Spencer ${ }^{17}$ na bactéria não patogênica Azotobacter vinelandii isolada do solo. Estes mesmos autores, em 1966, estudaram a produção de ácido algínico por Azotobacter vinelandii com especial atenção para as unidades que constituem a cadeia principal do polissacarídeo e observaram que o mesmo é constituído de unidades de ácido Dmanurônico e unidades de ácido L-gulurônico em menor proporção. Verificaram que a rotação específica do alginato de sódio bacteriano é muito próxima da rotação do alginato de sódio derivado de algas, sugerindo, assim, que as configurações glicosídicas de ambos os alginatos são similares.

\section{A bactéria Azotobacter vinelandii}

A família Azotobacteriaceae compreende as bactérias do gênero Azotobacter, as quais são eubactérias Gram-negativas que possuem uma parede celular complexa, que consiste de uma membrana externa e uma capa interna de peptideoglicano formado por unidades de ácido $\mathrm{N}$-acetil murâmico e $\mathrm{N}$-acetilglicosamina. Essas bactérias se reproduzem por fissão binária, vivem em solos e em águas frescas, possuem células ovóides e grandes com diâmetro de 1,5 a 2,0 $\mu \mathrm{m}$. Também podem apresentar como características o pleomorfismo, variando sua morfologia desde bacilos até células em forma de cocos. São encontradas como células individuais, em pares, em agregados de células irregulares e algumas vezes formando cadeias de tamanho variável. A sua movimentação é realizada por flagelos e, embora sejam aeróbias, estas bactérias podem crescer em concentrações baixas de oxigênio. ${ }^{38,39}$

As bactérias do gênero Azotobacter são quimio-organotróficas, utilizam açúcares, álcoois e sais inorgânicos para crescerem. Em vida livre, fixam em média $10 \mathrm{mg}$ de nitrogênio por grama de carboidrato (glicose) consumido e para esta atividade requerem molibdênio, que pode ser parcialmente substituído por vanádio. Como fontes de nitrogênio podem utilizar nitrato, sais de amônio e certos aminoácidos. $\mathrm{O}$ pH ótimo de crescimento quando fixam nitrogênio é de 7,0-7,5. Este gênero possui resposta positiva ao teste enzimático da catalase.

A Azotobacter vinelandii é uma bactéria poliplóide, cuja reprodução depende do meio de cultura e das condições de cultivo utilizadas, assim como da fase de crescimento em que o microrganismo se encontra. $\mathrm{O}$ volume da célula, quando a bactéria fixa nitrogênio, varia entre 2,7 a $6,6 \mu \mathrm{m}^{3}$, o que representa de 5 a 10 vezes mais o volume da E. coli. Este tamanho pode estar associado com o fato da A. vinelandii ser uma bactéria poliplóide. ${ }^{38}$

Contrastando $\operatorname{com} P$. aeruginosa, somente o alginato sintetizado pela $A$. vinelandii apresenta uma seqüência de monômeros na sua estrutura química similar ao obtido de algas ${ }^{40}$ sob várias condições de cultura, sendo esta bactéria considerada como fonte potencial de alginatos para fins técnicos. Diversos laboratórios industriais têm tentado elucidar a rota biossintética, as condições de crescimento e a fisiologia bacteriana que levam à produção de polissacarídeos. A. vinelandii produz exopolissacarídeo (EPS) quando cultivada em diversos meios à base de mono e dissacarídeos, como glicose, frutose, manose, sacarose, lactose e manitol. Uma relação C:N alta tem sido freqüentemente considerada como a condição ambiental mais significativa para o acúmulo de polissacarídeo. Estudos revelaram uma produção aumentada de exopolissacarídeo por A. vinelandii, sob condições de stress, para vários nutrientes..$^{22,41}$

Jarman e colaboradore ${ }^{42}$ pesquisaram o efeito das condições do ambiente na taxa de síntese e de crescimento durante a produção do EPS por Azotobacter vinelandii e observaram que a produção não é afetada pela maior parte das condições ambientais. Essa bactéria produziu quantidades substanciais de ácido algínico, sendo as taxas de produção similares entre si sob diversas condições ambientais. Estes autores, surpresos a princípio com tal observação, verificaram em estudos anteriores que pouca influência do ambiente sobre a produção de EPS não é incomum. ${ }^{43,44}$

\section{Efeitos da adição de fontes de carbono e fosfato inorgânico}

Horan e colaboradores ${ }^{45}$ estudaram as atividades específicas das enzimas-chave envolvidas na biossíntese de ácido algínico por Azotobacter vinelandii, em extratos destes organismos cultivados em batelada com diferentes fontes de carbono em meio com limitação de fosfato inorgânico, bem como, com excesso do mesmo. A produção de ácido algínico foi avaliada em meios contendo glicose, frutose, sorbitol, manitol, glicerol e gluconato, e foi observado que todas as fontes de carbono eram semelhantes à sacarose, no que se refere a suportar uma produção grande de alginato, em meio contendo quantidades de fosfato inorgânico consideradas "limitantes" para o crescimento. A manose resultou em um crescimento pobre, sob as mesmas condições, sem a produção de alginato, e não ocorreu crescimento quando foi utilizado acetato. Incrementos nas atividades específicas de fosfomanose isomerase, GDPmanose pirofosforilase e GDPmanose desidrogenase foram acompanhados de produções elevadas de ácido algínico. Estes autores notaram que tais resultados estavam de acordo com a sugestão de que a formação de alginato é controlada pela indução de enzimas-chave envolvidas na biossíntese desses polímeros.

Horan e colaboradore ${ }^{45}$ constataram que a quantidade de alginato produzida era dependente da concentração inicial de fosfato inorgânico tendo como única fonte de carbono sacarose, glicose, frutose, manitol, glicerol ou gluconato, de maneira que a produção aumentava significativamente conforme reduzia a concentração de fosfato.

Ainda com relação ao experimento de Horan e colaboradores, ${ }^{45}$ foi observado que durante o crescimento do microrganismo em meio com limitação de fosfato e com sacarose $\left(20 \mathrm{~g} \mathrm{~L}^{-1}\right)$ como única fonte de carbono, a produção de ácido algínico começou logo depois do início da fase de crescimento exponencial. $\mathrm{O}$ alginato era produzido em uma taxa relativamente baixa até que o crescimento cessou devido à exaustão do fosfato; daí então, a produção de ácido algínico aumentou significativamente e continuou por $40 \mathrm{~h}$. O fim da produção de ácido algínico não pôde ser atribuído à exaustão da fonte de carbono, uma vez que o sobrenadante da cultura continha ainda $6 \mathrm{~g}$ de sacarose por litro. Valores de $5 \mathrm{a} 7 \mathrm{~g}$ de alginato ( $\mathrm{g}$ matéria seca de bactéria) $)^{-1}$ foram observados, comparados com 1,5 $\mathrm{g}$ de alginato $(\mathrm{g}$ 
matéria seca de bactéria) ${ }^{-1}$ observados por Deavin e colaboradores ${ }^{43}$ quando trabalhavam com um tipo selvagem de microrganismo. Isto resultou numa cultura de alta viscosidade, causando severa limitação de oxigênio, com um aumento pronunciado no conteúdo de poli-3hidroxibutirato, o qual está associado com as Azotobacteriaceae cultivadas sob tais limitações. Durante a fase de crescimento exponencial, em meio com excesso de fosfato, a produção de alginato foi muito baixa (menor que $500 \mu \mathrm{g} \mathrm{mL}^{-1}$ ), e o crescimento cessou com fosfato $\left(0,8 \mathrm{~g} \mathrm{~L}^{-1}\right)$ e sacarose $\left(8 \mathrm{~g} \mathrm{~L}^{-1}\right)$ ainda presentes no meio. Na seqüência, a produção de alginato aumentou por $30 \mathrm{~h}$ e valores na faixa de 0,8 a 1,2 $\mathrm{g}$ de alginato (g matéria seca de bactéria) ${ }^{-1}$ foram observados rotineiramente. Nesta concentração de polissacarídeo a viscosidade da cultura era baixa e o conteúdo de poli-3-hidróxibutirato chegou num valor máximo de $7 \%$.

Okabe e colaboradores ${ }^{46}$ selecionaram uma cepa de Azotobacter vinelandii (N-II-1-2) e investigaram a influência de diferentes fontes de carbono e de fósforo no crescimento celular e na produção de ácido algínico. Glicose, manitol, maltose, frutose, sorbitol, sacarose, rafinose, e glicerol foram utilizados como fontes de carbono. Frutose e sorbitol foram excelentes para o crescimento, mas muito pobres para a produção de alginato, enquanto que o contrário disto foi observado para a glicose, manitol e maltose. Sacarose resultou em boa produção tanto de massa celular como de alginato. A ótima concentração de fosfato para o crescimento bacteriano em meio de Burk foi aproximadamente $5 \mathrm{mmol} \mathrm{L}^{-1}$. Com relação ao efeito da fonte de carbono, a produção de polissacarídeo foi maior para $1 \%$ sacarose, glicose, manitol e maltose, ou $0,5 \%$ rafinose, quando comparada com as demais fontes de carbono testadas, enquanto que a produção de massa celular foi maior para frutose, sorbitol e sacarose. Assim, a sacarose demonstrou ser a melhor fonte de carbono dentre todas as testadas. Quanto ao efeito de diferentes concentrações de sacarose como fonte de carbono, estes autores investigaram, em adição ao meio de Burk padrão contendo $2 \%$ de sacarose, meios similares contendo 1,4 e $8 \%$ de sacarose. Os resultados mostraram que, enquanto a massa celular seca aumentou juntamente com o aumento da concentração de sacarose, a produção de polissacarídeo se comportou de forma inversa. Desta forma, $1 \%$ foi considerada a melhor concentração para sacarose como fonte de carbono, fato também concluído por Emtiazi e colaboradores. ${ }^{47}$

Okabe e colaboradores ${ }^{46}$ observaram o crescimento celular e a produção de polissacarídeo em meio de Burk contendo várias concentrações de fosfato $\left(\mathrm{K}_{2} \mathrm{HPO}_{4}\right.$ e $\left.\mathrm{KH}_{2} \mathrm{PO}_{4}\right)$. A produção de polissacarídeo aumentou juntamente com o aumento da concentração de fosfato até $5,0 \mathrm{mmol} \mathrm{L}^{-1}$, e então começou a diminuir gradativamente. Em contraste, a massa bacteriana continuou a aumentar com a concentração de fosfato dentro da faixa testada. Uma vez que o meio de Burk padrão contém 4,9 mmol L-1 de fosfato, este meio é ótimo para produção de polissacarídeo no que se refere à sua concentração de fosfato. Estes pesquisadores estabeleceram uma relação entre produção de polissacarídeo e crescimento bacteriano. Eles observaram que o período de tempo para produção se comportou de forma diferente que o período de tempo para crescimento. Ambos atingiram o ponto máximo após 90-100 h, mas a fase lag do crescimento bacteriano foi muito maior que aquela da produção. ${ }^{46}$

Vargas-García e colaboradores ${ }^{48}$ investigaram a influência do ácido 4-hidroxibenzóico na biossíntese de EPS. Os fatores ambientais e nutricionais foram otimizados para a máxima produção de EPS. As maiores produções de EPS foram obtidas em meio livre de nitrogênio corrigido com ácido 4-hidroxibenzóico 20-30 mmol L-1. De modo geral, as modificações na concentração de sal inorgânico não alteraram a produção de EPS, com exceção do caso dos íons de magnésio. Níveis altos deste cátion foram relacionados com maiores produções de EPS. A produção foi altamente influenciada por certos fatores ambientais, sendo selecionadas as seguintes condições: $34^{\circ} \mathrm{C}$, $80 \mathrm{rpm}$, num meio neutro ou levemente alcalino. Sob tais condições, mais de $25 \%$ da fonte de carbono fornecida foi convertida em EPS e a produção foi melhorada cerca de $42 \%$ quando comparada com aquela observada no meio inicial.

A produção de alginato em meio à base de glicose por $A$. vinelandii DSM 576 foi estudada, em frascos sob agitação, para diferentes temperaturas $\left(23-42^{\circ} \mathrm{C}\right)$, diferentes velocidades de agitação (250-450 $\left.\mathrm{min}^{-1}\right)$ e diferentes concentrações iniciais de glicose $\left(10-100 \mathrm{~g} \mathrm{~L}^{-1}\right)$. Quando o meio de cultura foi tamponado, a produção de alginato e de biomassa bacteriana foram otimizadas com relação à razão $\mathrm{C}: \mathrm{N} \mathrm{e}$ as concentrações de acetato e fosfato. ${ }^{1}$ Neste estudo, a limitação de fosfato $\left(0,035 \mathrm{~g} \mathrm{~L}^{-1}\right)$ e a não adição de acetato resultou em produção máxima de alginato em relação ao caso de excesso de fosfato $(3,5 \mathrm{~g}$ $\left.\mathrm{L}^{-1}\right)$ e acetato $\left(3 \mathrm{~g} \mathrm{~L}^{-1}\right){ }^{1}$

\section{Efeitos da adição de fontes de carbono e variação da taxa de aeração}

Horan e colaboradores ${ }^{49}$ notaram que quando um mutante de Azotobacter vinelandii era cultivado em cultura contínua, a quantidade de polissacarídeo produzida dependia da concentração de oxigênio dissolvido e também da fonte de carbono: sacarose suportava a síntese de alginato em meio com limitação de fosfato, enquanto que o sorbitol não suportava. Mudanças na atividade específica de enzimas-chave na biossíntese de alginato (fosfomanose isomerase e GDPmanose pirofosforilase), medidos em extratos de células crescidas dentro de uma faixa de valores de concentração de oxigênio dissolvido, eram refletidas pelas mudanças observadas na produção de alginato, enquanto que a atividade de GDPmanose desidrogenase ficava inalterada. Uma correlação similar entre as atividades específicas destas enzimas e a taxa de produção de alginato foi observada neste estudo durante a transição de sorbitol para sacarose como única fonte de carbono, mas a atividade da GDPmanose desidrogenase também aumentou com o aumento da produção de alginato. Depois de prolongado cultivo contínuo em sacarose, a mutante perdeu a habilidade de produzir alginato. As enzimas-chave na biossíntese de alginato não foram detectadas em extratos desta cepa não produtora de alginato, a qual tinha também perdido a habilidade de formar cisto. Estes resultados suportam a opinião de que a formação de alginato é controlada pela indução de enzimas-chave na biossíntese de alginato, bem como que o alginato tem um importante papel na formação de cistos pelas bactérias. ${ }^{49}$

Alguns fatores que influenciam na produção de ácido algínico por Azotobacter vinelandii foram investigados, em cultura por batelada, por Brivonese e Sutherland. ${ }^{23}$ Foi observado que as maiores produções de alginato $\left(6,0-7,5 \mathrm{mg} \mathrm{mL}^{-1}\right.$ sobrenadante) ocorreram em meio rico em nitrogênio e fosfato (PNR), tendo a glicose como fonte de carbono, aerando-se o meio com agitação a $280 \mathrm{rpm}$. A importância do oxigênio ficou evidente quando, a $120 \mathrm{rpm}$, a produção de alginato caiu para $1,4 \mathrm{mg} \mathrm{mL}^{-1}$. A $120 \mathrm{rpm}$ o acúmulo intracelular de ácido poli- $\beta$-hidroxibutírico (um polímero cujo acúmulo intracelular é associado com a limitação de oxigênio) foi de 40 contra $30 \%$ a 280 $\mathrm{rpm}$. A presença de fosfato inorgânico em PNR foi considerada importante, pois o crescimento em meios com baixo teor de sais resultou em produção pobre de alginato, a qual não foi melhorada pela adição de fontes de nitrogênio, como o nitrato e glutamato. A substituição da glicose por sacarose também reduziu a produção de alginato. Em estudo semelhante, Savalgi e Savalgi ${ }^{50}$ verificaram que as maiores quantidades de ácido algínico produzidas por Azotobacter vinelandii NCIB 9068 (5,5-6,2 $\mathrm{mg} \mathrm{mL}^{-1}$ sobrenadante), em frascos agitados, foram obtidas quando o crescimento foi conduzido em um meio rico em nitrogênio mas com limitação de fosfato, tendo a sacarose como fonte de carbono, sob agitação a $240 \mathrm{rpm}$. Também se observou a 
redução na produção de alginato para $1,6 \mathrm{mg} \mathrm{mL}^{-1}$, com a diminuição da agitação (140 rpm). Em contraste com Brivonese e Sutherland, ${ }^{23}$ a substituição da sacarose por glicose reduziu o crescimento bem como a produção de alginato.

O efeito de diferentes condições de aeração, durante o cultivo de Azotobacter vinelandii, sobre a produção e a massa molecular do alginato, foi avaliado em frascos agitados por Peña e colaboradores. ${ }^{51}$ Paletas de vidro foram colocadas no interior de alguns frascos erlenmyer, as quais funcionaram como um obstáculo para o líquido durante a agitação, com a finalidade de aumentar a aeração. Nos frascos erlenmeyer com paletas, a bactéria cresceu mais rápido e produziu menos alginato $\left(1,5 \mathrm{~g} \mathrm{~L}^{-1}\right)$ que em frascos erlenmeyer convencionais (sem as paletas) $\left(4,5 \mathrm{~g} \mathrm{~L}^{-1}\right)$. A viscosidade do caldo de cultura também foi influenciada pelo tipo de frasco. Viscosidades finais maiores foram obtidas nos frascos erlenmeyer convencionais [520 cP (520 mPa.s)] quando comparadas com aqueles dotados de paletas $(30 \mathrm{cP})$. Este último fenômeno esteve relacionado de perto com as mudanças na distribuição da massa molecular. Em ambos os casos, a média da massa molecular aumentou com a idade da cultura; entretanto, ao final da fermentação, a massa molecular média do alginato obtido em frascos erlenmeyer convencionais era cinco vezes maior que a obtida naqueles providos de paletas de vidro. A velocidade e a temperatura de agitação do experimento foram de $200 \mathrm{rpm}$ e $29^{\circ} \mathrm{C}$. Estes autores obtiveram uma concentração máxima de alginato $(4,5 \mathrm{~g}$ $\mathrm{L}^{-1}$ ) em frascos erlenmeyer convencionais após $72 \mathrm{~h}$ de cultura, enquanto apenas $1,4 \mathrm{~g} \mathrm{~L}^{-1}$ de alginato foram produzidas naqueles frascos providos de paletas de vidro, neste mesmo período. Nos frascos erlenmeyer convencionais, a produção de alginato esteve parcialmente associada com o crescimento, de modo que uma fração importante da produção total aconteceu na fase estacionária do crescimento. Em frascos erlenmeyer com paletas, a bactéria produziu a maior parte do polissacarídeo no final da fase estacionária. Os resultados obtidos por Peña e colaboradores ${ }^{52}$ mostraram que a cultura cresceu mais rapidamente em frascos erlenmeyer providos de placas de vidro (taxa de crescimento específico, $\mu=0,15 \mathrm{~h}^{-1}$ ) que nos convencionais $\left(\mu=0,09 \mathrm{~h}^{-1}\right)$. Isto foi uma indicação clara de que o crescimento bacteriano nos frascos convencionais estava limitado pela menor oxigenação, já que nos frascos erlenmeyer providos de placa de vidro em seu interior a oxigenação foi melhor. ${ }^{51}$ Em contraste com este fato, uma maior concentração de alginato foi obtida sob baixas condições de aeração (frascos erlenmeyers convencionais). Este fenômeno pode estar relacionado com a sensibilidade ao oxigênio apresentada por algumas enzimas envolvidas na biossíntese do alginato por Azotobacter vinelandii. ${ }^{49}$ Os resultados de Peña e colaboradores ${ }^{52}$ estão de acordo com aqueles observados por Chen e colaboradores, ${ }^{53}$ que indicaram que a concentração de alginato era maior a $170 \mathrm{rpm}$ (para valores de rpm entre 110 e 200) para uma cultura de Azotobacter vinelandii conduzida em frascos agitados. Um aumento da velocidade de agitação (i.e., maior aeração) era desfavorável para a produção de alginato.

A viscosidade do caldo de cultura foi maior quando sob menor aeração. Isto sugere um efeito importante do oxigênio nas características moleculares (i.e., massa molecular) do polímero. Sabe-se que a viscosidade de soluções de alginato é influenciada grandemente pela distribuição da massa molecular, mas não tanto pelo conteúdo e distribuição dos dois monômeros da molécula de alginato.$^{54}$ Entretanto, não há dados anteriores publicados sobre a viscosidade do caldo de cultura sob diferentes condições de cultivo. Peña e colaboradores ${ }^{52}$ observaram que o grau de acetilação do alginato produzido por $A$. vinelandii era independente das condições de aeração.

Num estudo de produção de alginato por Azotobacter vinelandii DSM 576, em fermentação por batelada, Parente e colaboradores ${ }^{55}$ constataram que nenhum alginato foi produzido a $10 \%$ de oxigênio dissolvido (OD). Eles estudaram a produção de alginato para 1, 2, 5 e $10 \%$ OD. A produção foi mais rápida a 2 e $5 \%$ OD, entretanto, as mais elevadas produções de alginato foram obtidas sem o controle de
OD. A produção de alginato foi associada ao crescimento a 5\% OD, mas quantidades significativas de alginato foram produzidas depois que o crescimento parou sob menores valores de OD. Nas fermentações sem controle de OD, o peso molecular do polímero atingiu um máximo (11-17,6 x 104 Dalton) quando a taxa de crescimento específico $(\mu)$ estava entre 0,02 e $0,04 \mathrm{~h}^{-1}$ e a concentração residual de nitrogênio amoniacal estava entre 0,01 e $0,02 \mathrm{~g} \mathrm{~L}^{-1}$, e depois decresceu abruptamente. Estas observações foram feitas para um meio à base de glicose, rico em nitrogênio e fosfato, $\mathrm{pH} 7$ e $35^{\circ} \mathrm{C} . .^{55}$

Num estudo posterior, Peña e colaboradore ${ }^{51}$ verificaram que tanto a concentração de oxigênio como a velocidade de agitação ocupam um importante papel na síntese de alginato bem como na composição do polímero. De fato, estes autores observaram que a produção de alginato por Azotobacter vinelandii, bem como o peso molecular do polímero, foram grandemente influenciados pela concentração de oxigênio dissolvido (OD) e velocidade de agitação da cultura. Sob um alto índice de OD (5\% de saturação de ar) a bactéria produziu mais alginato $\left(4,5 \mathrm{~g} \mathrm{~L}^{-1}\right)$ quando comparado com $0,5 \%$ OD em culturas submetidas a $300 \mathrm{rpm}$, pois nesse caso a produção de alginato foi de apenas $1,0 \mathrm{~g} \mathrm{~L}^{-1}$. Por outro lado, sob OD constante (3\%), quanto maior a velocidade de agitação (de 300 a 700 $\mathrm{rpm}$ ), maior a taxa de crescimento específico e também a taxa de produção de alginato. Entretanto, uma baixa velocidade de agitação (300 rpm) levou à produção de um polímero de alto peso molecular $\left(680000 \mathrm{~g}(\mathrm{~g} \mathrm{~mol})^{-1}\right)$, enquanto que um alginato de baixo peso molecular $\left(352000 \mathrm{~g}(\mathrm{~g} \mathrm{~mol})^{-1}\right)$ foi isolado de culturas submetidas sob alta velocidade de agitação (700 rpm). Sob $700 \mathrm{rpm}$, o peso molecular aumentou até um patamar entre $1 \mathrm{e}$ $3 \%$ OD e, então decresceu até um mínimo de $0,11 \times 10^{6} \mathrm{~g}(\mathrm{~g} \mathrm{~mol})^{-1}$ a $7 \%$ OD. Observações microscópicas revelaram a presença de agregados de células (uma ordem de magnitude maior que células individuais) quando a cultura foi conduzida a $300 \mathrm{rpm}$. Gradientes de oxigênio ocorrendo dentro dos agregados poderiam ser os responsáveis por este fenômeno.

\section{Efeitos da variação da temperatura de incubação e pH}

Vermani e colaboradores ${ }^{56}$ verificaram que Azotobacter vinelandii MTCC, isolado da rizosfera de Nelumbium nelumbo (lótus), tem um grande potencial para produzir alginato em escala industrial. Estes pesquisadores obtiveram, em frascos agitados, uma produção final de $30 \%$ da quantidade de fonte de carbono fornecida (sacarose), sendo 25 ${ }^{\circ} \mathrm{C}$ a melhor temperatura para crescimento e $30^{\circ} \mathrm{C}$ a melhor temperatura para a síntese de exopolissacarídeo. A produção foi maior em $\mathrm{pH} 5$ e 6 , decrescendo para maiores valores de $\mathrm{pH}$. Estes autores comentam que, apesar da $A$. vinelandii ser uma bactéria fixadora de nitrogênio, este foi fornecido visando diminuir a fase lag. Tanto o crescimento quanto a produção de EPS foi aumentada com o fornecimento de nitrogênio na forma de $\mathrm{NaNO}_{3}$. A recuperação de EPS foi ainda maior quando nitrogênio foi fornecido na forma de $\mathrm{KNO}_{3}$. Dentre os sais, foi observado que $\mathrm{CaCO}_{3}$ é essencial tanto para o crescimento quanto para a síntese de EPS, enquanto que $\mathrm{MgSO}_{4}$ é essencial para a síntese de EPS sem efeito perceptível no crescimento. A sacarose foi considerada melhor fonte de carbono que a glicose para a síntese de EPS.

Clementi e colaboradores ${ }^{1}$ observaram que a taxa de síntese de alginato cai rapidamente a zero como resultado de uma queda drástica no $\mathrm{pH}$ numa cultura de $A$. vinelandii. Entretanto, no estudo de Peña e colaboradore ${ }^{52}$ a taxa de formação de alginato não foi afetada pela queda de $\mathrm{pH}$ experimentada na fase estacionária de crescimento.

\section{Culturas microbianas livres e imobilizadas}

Lebrun e colaboradores ${ }^{57}$ estudaram a produção em batelada de alginato, xantana, pululana e dextrana, por culturas microbianas livres e imobilizadas num arranjo do tipo camada de ágar/membrana microporosa. Dos quatro exopolissacarídeos estudados, apenas algi- 
nato, de Azotobacter vinelandii, e numa escala menor, a dextrana, de Leuconostoc mesenteroides, foram produzidos por culturas imobilizadas. Segundo estes autores, a produção de alginato por culturas imobilizadas de $A$. vinelandii parece ser um modelo adequado para monitorar variações nas características do polissacarídeo após sucessivas fermentações por batelada e, de modo geral, para estudar os efeitos da imobilização na biossíntese de exopolissacarídeos.

$\mathrm{O}$ peso molecular do alginato produzido por culturas livres e imobilizadas (arranjo ágar-gel em camada/membrana microporosa) de Azotobacter vinelandii foi estudado por Saude e Junter. ${ }^{58} \mathrm{~A}$ imobilização se mostrou favorável à produção de macromoléculas de alginato de alto peso molecular, bem como à uniformização da distribuição do peso molecular do alginato produzido, quando comparada com o alginato obtido a partir de culturas convencionais de células livres em frascos agitados.

\section{Extração e separação do alginato bacteriano}

Os exopolissacarídeos (EPS) são facilmente solubilizados e podem ser simplesmente isolados, de preferência, na sua forma homogeneizada por centrifugação e as células descartadas. A rotação e o tempo de centrifugação dependem da viscosidade dos polissacarídeos. ${ }^{59}$

Após o procedimento de separação das células bacterianas e do sobrenadante é necessário realizar a precipitação do alginato. As técnicas normalmente utilizadas para a precipitação de EPS bacterianos incluem a adição de etanol, acetona, propanol, isopropanol, brometo de cetiltrimetilamônio (CTAB) e 3,5,6 - trifenil - 2,3,5,6 tetraaza biciclo-1-hexeno (comercialmente conhecido como Nitron.
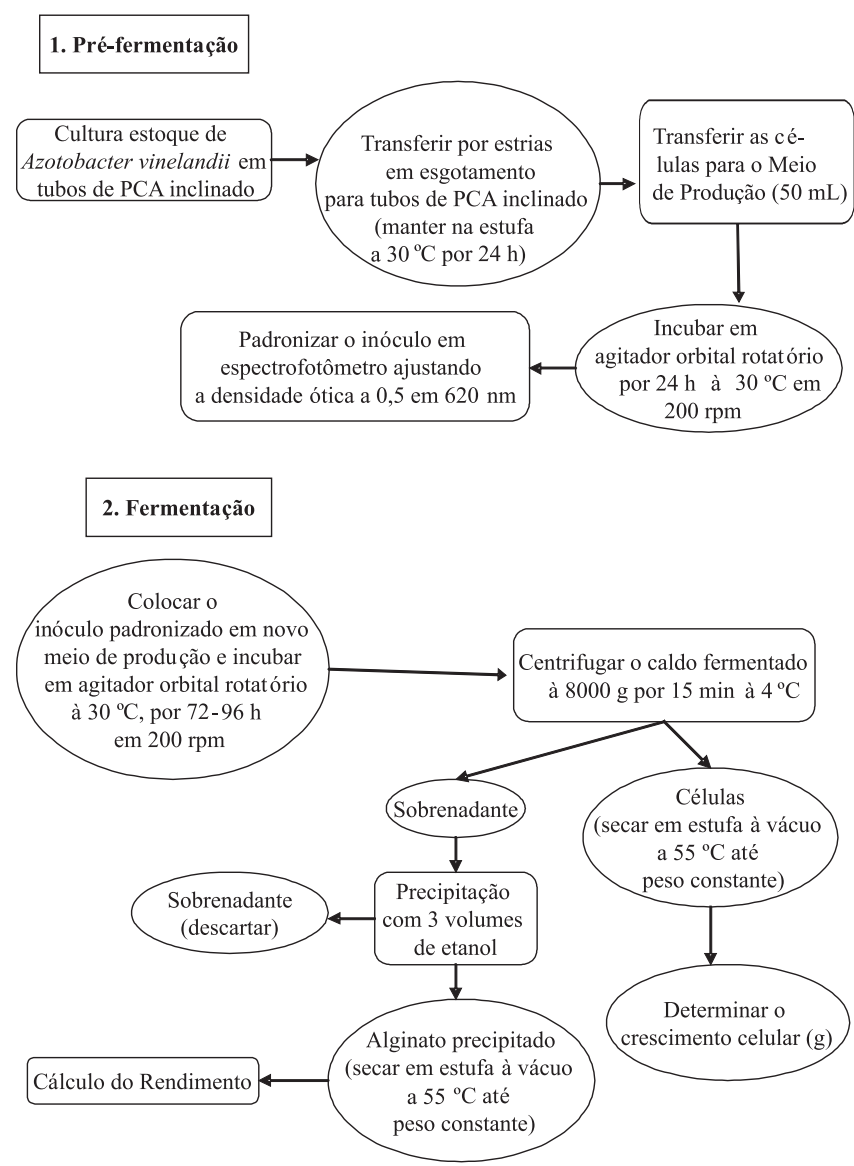

Figura 2. Diagrama de produção e extração do alginato bacteriano. Adaptada da ref. 63
Azevedo \& Oliveira, 1996).$^{60}$

Saude e colaboradores ${ }^{58}$ extraíram o alginato bacteriano por meio da precipitação do sobrenadante livre de células com etanol $(95 \%$ $\mathrm{vol} / \mathrm{vol}$ ), entretanto utilizaram a proporção 2 volumes de etanol:1 volume do sobrenadante. Em seguida, realizaram uma centrifugação (3500 g, $30 \mathrm{~min}$ ) seguida de 3 diálises contra EDTA $50 \mathrm{mmol} \mathrm{L}^{-1}$. Os tubos de diálise foram lavados três vezes em água destilada por $3 \mathrm{~h}$. $\mathrm{O}$ alginato foi seco por congelamento (procedimento feito em $24 \mathrm{~h}$ ) e, em seguida, pesado. ${ }^{61}$

Clementi e colaboradores ${ }^{1}$ realizaram a centrifugação do caldo fermentado a $11000 \mathrm{~min}^{-1}$ à $4{ }^{\circ} \mathrm{C}$ por $30 \mathrm{~min}$. O sobrenadante foi tratado com etanol $(95 \% \mathrm{vol} / \mathrm{vol})$ resfriado a $0{ }^{\circ} \mathrm{C}$ na proporção 3 volumes de etanol:1 volume do sobrenadante. Após a centrifugação a $9500 \mathrm{~min}^{-1}$ à $4{ }^{\circ} \mathrm{C}$ por $30 \mathrm{~min}$, o precipitado foi seco à $90{ }^{\circ} \mathrm{C}$ até peso constante e, em seguida, foi expressa a concentração de alginato em gramas por litro de caldo fermentado. A concentração do EPS também foi analisada por espectrofotometria utilizando para isto o sobrenadante do caldo fermentado.

Em geral, a produção e extração do alginato bacteriano seguem a metodologia descrita na Figura 2. A primeira etapa consiste na préfermentação, onde a cultura estoque de $A$. vinelandii mantida em tubos de PCA inclinado é transferida para tubos de PCA inclinado novos e mantidos em estufa a $30{ }^{\circ} \mathrm{C}$ por $24 \mathrm{~h}$. Em seguida, o crescimento bacteriano é transferido para o meio de produção $(50 \mathrm{~mL})$, contendo uma fonte de carbono e sais minerais, incubado em agitador orbital rotatório por $24 \mathrm{~h}$ a $30^{\circ} \mathrm{C}$ em $200 \mathrm{rpm}$. Após este período de incubação é realizada a padronização do inóculo utilizando um espectrofotômetro até atingir uma densidade ótica pré-determinada $(0,5)$ à $620 \mathrm{~nm} .{ }^{62}$ Em seguida, é iniciada a etapa de fermentação, na qual o inóculo padronizado é adicionado ao meio de cultura novo e incubado a $30^{\circ} \mathrm{C}$ e $200 \mathrm{rpm}$ em agitador orbital rotatório durante 72-96 h. Logo após o término da incubação, o caldo fermentado é centrifugado a $8000 \mathrm{~g}$ por 15 min na temperatura de $4{ }^{\circ} \mathrm{C}$ para a separação das células que, posteriormente, são secas em estufa a vácuo na temperatura de 55 ${ }^{\circ} \mathrm{C}$ até peso constante para quantificar o crescimento bacteriano. No sobrenadante, em geral são adicionados, 3 volumes de etanol para que ocorra a precipitação do alginato, em seguida, o sobrenadante resultante pode ser descartado ou concentrado e re-precipitado novamente. $\mathrm{O}$ precipitado (alginato) é seco em estufa a vácuo na temperatura de $55^{\circ} \mathrm{C}$ até peso constante. Em seguida, é calculado o rendimento em $\mathrm{g}$ de alginato $(\mathrm{mL} \text { de caldo fermentado })^{-1}$.

\section{CONCLUSÕES}

O alginato bacteriano é mais vantajoso que o alginato de algas, pois devido às suas características estruturais - maior variabilidade na distribuição dos blocos "G" na molécula - oferece maior gama de opções para aplicação na indústria. Os parâmetros de produção podem ser controlados em laboratório e estes não sofrem influência de variações sazonais e mudanças climáticas como acontece com as algas marinhas e também não necessita da adição de formaldeído em nenhuma etapa; em contrapartida, é necessário o uso deste composto nas algas para preservar o material de extração do alginato. $\mathrm{O}$ grau de acetilação elevado no alginato bacteriano pode produzir géis muito fortes e quebradiços, mas este problema pode ser resolvido promovendo-se uma desacetilação ou pela adição cuidadosamente controlada de cálcio.

\section{REFERÊNCIAS}

1. Clementi, F.; Fantozzi, P.; Mancini, F.; Moresi, M.; Enzyme Microb. Technol. 1995, 17, 983.

2. Oakenfull, D.; Crit. Rev. Food Sci. Nutr. 1987, 26, 1. 
3. Glicksman, M.; Alim. Tecnol. 1986, 12, 43.

4. Moen, E.; Larsen, B.; Ostgaard, K.; Jensen, A.; J. Appl. Phycol. 1999, $11,21$.

5. Crescenzi, V.; Biotechnol. Prog. 1995, 11, 251.

6. Remminghorst, U.; Rhem, B. H. A.; Biotechnol. Lett. 2006, $28,1701$.

7. Rhem, B. H. A.; Valla, S.; Appl. Microbiol. Biotechnol. 1997, 48, 281.

8. Sabra, W.; Zeng, A. P.; Deckwer, W. D.; Microbiol. Biotechnol. 2001, 56,315 .

9. Smidsrod, O.; Carbohydr. Res. 1970, 13, 359.

10. Clementi, F.; Crit. Rev. Biotechnol. 1997, 17, 327.

11. Nussinovitch, A. Em Hydrocolloid Applications: gum technology in the food and other industries; Nussinovitch, A., eds.; Blackie Academic \& Professional: London, 1997.

12. Skajak-Braek, G.; Larsen, B.; Smidsrod, O.; Int. J. Biol. Macromol. 1986, $8,330$.

13. Xiao, L.; Han, F.; Yang, Z.; Lu, X.; Yu, W.; World J. Microbiol. Biotechnol. 2006, 22, 81.

14. Espevik, T.; Otterlei, M.; Skjak-Braek, G.; Ryan, L.; Wright, S. D.; Sundan, A.; Eur. J. Immunol. 1993, 23, 255.

15. Smidsrod, O.; Draget, K. I.; Carbohydr. Eur. 1996, 14, 6.

16. Cote, G. L.; Krull, L. H.; Carbohydr. Res. 1988, 181, 143.

17. Gorin, P. A. J.; Spencer, J. F. T.; Can. J. Chem. 1966, 44, 993.

18. Govan, J. R. W.; Fyfe, J. F. M.; Jarman, T. R.; J. Gen. Microbiol. 1981, 125, 217.

19. Jimenéz, R. P.; Peña, C.; Ramírez, O. T.; Galindo, E.; Biochem. Eng. J. 2005, 25, 187.

20. Linker, A.; Jones, R. S.; J. Biol. Chem. 1966, 241, 3845.

21. Peña, C.; Hernández, L.; Galindo, E.; Lett. Appl. Microbiol. 2006, 43, 200.

22. Moe, S. T.; Draget, K. I.; Skjak-Braek, G.; Smidsrod, O. Em Alginates; Moe, S. T.; Draget, K. I.; Skjak-Braek, G.; Smidsrod, O., eds.; Marcel Dekker: New York, 1995.

23. Brivonese, A. C.; Sutherland, I. W.; Appl. Microbiol. Biotechnol. 1989, $30,97$.

24. Alkawash, M. A.; Soothill, J. S.; Schiller, N. L.; APMIS 2006, 8, 114.

25. Govan, J. R. W.; Harris, G. S.; Microbiol. Sci. 1986, 3, 302.

26. May, T. B.; Chakrabarty, A. M.; Trends Microbiol. 1994, 2, 151.

27. Gacesa, P.; Russell, N. J. Em The structure and property of alginate; Gacesa, P.; Russell, N. J., eds.; Chapman \& Hall: London, 1990.

28. Sadoff, H. L.; Bacteriol. Rev. 1975, 39, 516.

29. Clementi, F.; Crudele, M. A.; Parente, E.; Mancini, M.; Moresi, M.; J. Sci. Food Agric. 1999, 79, 602.

30. Giulio, B.; Orlando, P.; Barba, G.; Coppola, R.; Rosa, M.; Sada, A.; Prisco, P. P.; Nazzaro, F.; World J. Microbiol. Biotechnol. 2005, 21, 739.

31. Onsoyen, E.; Carbohydr. Eur. 1996, 4, 26.

32. Smidsrod, O.; Skajak-Braek, G.; Trends Biotechnol. 1990, 8, 71.

33. Glicksman, M.; Alim. Tecnol. 1987, 13, 58.

34. Bueno, S. M.; Garcia-Cruz, C. H.; Braz. J. Microbiol. 2006, 37, 260.

35. Coltro, A. L.; Garcia-Cruz, C. H.; Hig. Alim. 2006, 112, 38.

36. Faria, L. H. G. B.; Dissertação de Mestrado, Universidade Estadual Paulista, Brasil, 2002.

37. Garcia-Cruz, C. H.; Tese de Livre Docente, Universidade Estadual Paulista, Brasil, 1997.
38. Allman, R.; Hann, A. C.; Phillips, A. P.; Martin, K. L.; Lloyde, D.; Cytometry 1990, 11, 822 .

39. Vargas-García, M. C.; López M. J.; Elorrieta, M. A.; Suárez, F.; Moreno, J.; J. Ind. Microbiol. Biotechnol. 2002, 29, 129.

40. Galindo, E.; Peña, C.; Núñez, C.; Segura, D.; Espín, G.; Microbial Cell Fact. 2007, 6, 7.

41. Pindar, D. F.; Bucke, C.; Biochem. J. 1975, 152, 617.

42. Jarman, T. R.; Deavin, L.; Slocombre, S.; Righelato, R. C.; J. Gen. Microbiol. 1978, 107, 59.

43. Deavin, L.; Jarman, T. R.; Lawson, C. J.; Righelato, R. C.; Slocombre, $\mathrm{S}$. Em The production of alginic acid by Azotobacter vinelandii in batch and continuous culture; Deavin, L.; Jarman, T. R.; Lawson, C. J.; Righelato, R. C.; Slocombre, S., eds.; American Chemical Society: Washington, 1977.

44. Silman, R. W.; Rogovin, P.; Biotechnol. Bioeng. 1972, 14, 23.

45. Horan, N. J.; Jarman, T. R.; Dawes, E. A.; J. Gen. Microbiol. 1981, 127 , 185.

46. Okabe, E.; Nakajima, M.; Murooka, H.; Nisizawa, K.; J. Fermentation Technol. 1981, 59, 1.

47. Emtiazi, G.; Ethemadifar, Z.; Habibi, M. H.; Afr. J. Biotechnol. 2004, 3, 330.

48. Vargas-García, M. C.; López, M. J.; Elorrieta, M. A.; Suárez, F.; Moreno, J.; J. Ind. Microbiol. Biotechnol. 2001, 27, 5.

49. Horan, N. J.; Jarman, T. R.; Dawes, E. A.; Gen. Microbiol. 1983, 129 , 2985.

50. Savalgi, V.; Savalgi, V.; J. Gen. Appl. Microbiol. 1992, 38, 641.

51. Peña, C.; Trujillo-Roldán, M. A.; Galindo, E.; Enzyme Microb. Technol. 2000, 27, 390.

52. Peña, C.; Campos, N.; Galindo, E.; Appl. Microbiol. Biotechnol. 1997, $48,510$.

53. Chen, W.; Chen, J.; Chang, S.; Su, C.; Appl. Environ. Microbiol. 1985, $49,543$.

54. Martinsen, A.; Skjak-Braek, G.; Smidsrod, O.; Zanetti, F.; Paoletti, S.; Carbohyd. Polym. 1991, 15, 171.

55. Parente, E.; Crudele, M. A.; Aquino, M.; Clementi, F.; J. Ind. Microbiol. Biotechnol. 1998, 20, 171.

56. Vermani, M. V.; Kelkar, S. M.; Kamat, M. Y.; J. Fermentation Bioeng. 1995, 80, 599.

57. Lebrun, L.; Junter, G. A.; Jouenne, T.; Mignot, L.; Enzyme Microb. Technol. 1994, 16, 1048.

58. Saude, N.; Junter, G. A.; Process Biochem. 2002, 37, 895.

59. Graber, M.; Morin, A.; Duchiron, F.; Monsan, P. F.; Enzyme Microb. Technol. 1988, 10, 198.

60. Goh, K. K. T.; Haisman, D. R.; Archer, R. H.; Singh, H.; Food Res. Int. 2005, 38, 605 .

61. Saude, N.; Chèze-Lange, H.; Beunard, D.; Dhulster, P.; Guillochon, D.; Cazé, A. M.; Morcellet, M.; Junter, G. A.; Process Biochem. 2002, 38 , 273.

62. Page, W. J.; Knosp, O.; Appl. Environ. Microbiol. 1989, 55, 1334.

63. Garcia-Cruz, C. H.; Dissertação de Mestrado, Universidade Estadual de Campinas, Brasil, 1982. 